Thermal characteristics, Raman spectra, optical and structural properties of $\mathrm{TiO}_{2}$ $\mathrm{Bi}_{2} \mathrm{O}_{3}-\mathrm{B}_{2} \mathrm{O}_{3}-\mathrm{TeO}_{2}$ glasses

Nupur Gupta, Atul Khanna, Fernando Gonzàlez, and Reni Iordanova

Citation: AIP Conference Proceedings 1832, 070005 (2017); doi: 10.1063/1.4980440

View online: http://dx.doi.org/10.1063/1.4980440

View Table of Contents: http://aip.scitation.org/toc/apc/1832/1

Published by the American Institute of Physics 


\title{
Thermal Characteristics, Raman Spectra, Optical and Structural Properties of $\mathrm{TiO}_{2}-\mathrm{Bi}_{2} \mathrm{O}_{3}-\mathrm{B}_{2} \mathrm{O}_{3}-\mathrm{TeO}_{2}$ Glasses
}

\author{
Nupur Gupta ${ }^{1}$, Atul Khanna ${ }^{1 *}$, Fernando Gonzàlez ${ }^{2}$, Reni Iordanova ${ }^{3}$ \\ ${ }^{1}$ Sensors and Glasses Physics Laboratory, Department of Physics, Guru Nanak Dev University, Amritsar-143005, \\ Punjab, India \\ ${ }^{2}$ Department of Chemistry and Process \& Recourse Engineering, University of Cantabria, Santander-39005, Spain \\ ${ }^{3}$ Institute of General and Inorganic Chemistry, Bulgarian Academy of Sciences, Acad. G. Bonchev Str. Blvd. 11, \\ 1113 Sofia, Bulgaria \\ *Email:atul.phy@gndu.ac.in
}

\begin{abstract}
Tellurite and borotellurite glasses containing $\mathrm{Bi}_{2} \mathrm{O}_{3}$ and $\mathrm{TiO}_{2}$ were prepared and structure-property correlations were carried out by density measurements, X-ray Diffraction (XRD), Differential Scanning Calorimetry (DSC), Raman and UV-visible spectroscopy. Titanium tellurite glasses require high melt-cooling rates and were fabricated by splat quenching. On adding $\mathrm{B}_{2} \mathrm{O}_{3}$, the glass forming ability (GFA) enhances, and glasses could be synthesized at lower quenching rates. The density of glasses shows a direct correlation with molecular mass of the constituents. UV-visible studies were used to determine the optical band gap and refractive index. Raman studies found that the co-ordination number of tellurium ions with oxygen $\left(\mathrm{N}_{\text {Te-O }}\right)$ decreases with the increase in $\mathrm{B}_{2} \mathrm{O}_{3}$ as well as $\mathrm{Bi}_{2} \mathrm{O}_{3}$ content while, $\mathrm{TiO}_{2}$ produce only a small decrease in $\mathrm{N}_{\mathrm{Te}-\mathrm{O}}$, which explains the lower GFA of titanium tellurite glasses that do not contain $\mathrm{Bi}_{2} \mathrm{O}_{3}$ and $\mathrm{B}_{2} \mathrm{O}_{3}$. DSC studies show that the glass transition temperature $\left(\mathrm{T}_{\mathrm{g}}\right)$ increases with $\mathrm{B}_{2} \mathrm{O}_{3}$ and $\mathrm{TiO}_{2}$ concentrations and that $\mathrm{T}_{\mathrm{g}}$ correlates well with bond enthalpy of the metal oxides.
\end{abstract}

Keywords: Tellurite and Borotellurite glasses, X-Ray Diffraction, Differential scanning calorimetry, Raman spectroscopy

PACS: 64.70.kj, 61.05.cp, 65.60.+a, 33.20.Fb.

\section{INTRODUCTION}

Tellurium oxide-based glasses have found remarkable technological applications due to their unique physical properties such as high refractive index, non-linear optical properties, high dielectric constant, wide optical transmission window [1]. The ab-initio studies show that the higher order of hyperpolarizability is inherent exclusively to the molecules having the form of linear chains formed from ' $n$ ' polymerized Te-O species [2].

The ternary $\mathrm{TeO}_{2}$-based glassy systems containing $\mathrm{TiO}_{2}$ modifier, jointly with $\mathrm{Bi}_{2} \mathrm{O}_{3}$ produces glasses which offer the best compromise on the high nonlinear optical characteristics and the high mechanical and thermal resistance [3].

$\mathrm{Bi}_{2} \mathrm{O}_{3}$ is added to borotellurite glass to increase its density and to improve its structural and optical properties. The borotellurite glasses contain $\mathrm{BO}_{4}$ tetrahedral, $\mathrm{BO}_{3}$ trigonal units, $\mathrm{TeO}_{4}$ trigonal bipyramidal, $\mathrm{TeO}_{3}$ pyramidal and $\mathrm{TeO}_{6}$ octahedral units at a high $\mathrm{B}_{2} \mathrm{O}_{3}$ content [4]. The aim of this work is to study the glass forming ability (GFA) of tellurite and borotellurite glasses containing $\mathrm{Bi}_{2} \mathrm{O}_{3}$ and $\mathrm{TiO}_{2}$ and perform structure-property correlations by Differential Scanning Calorimetry (DSC), UV-Visible and Raman Spectroscopy.

\section{EXPERIMENTAL}

Tellurite and borotellurite glasses containing $\mathrm{Bi}_{2} \mathrm{O}_{3}$ and $\mathrm{TiO}_{2}$ with composition: $\mathrm{xTiO}_{2}-\mathrm{yBi}_{2} \mathrm{O}_{3}-\mathrm{zB}_{2} \mathrm{O}_{3}$ (100-x-y-z) $\mathrm{TeO}_{2}(\mathrm{x}=5,10-\mathrm{mol} \%, \mathrm{y}=5,20$ and 30-mol $\%, \mathrm{z}=20$ and $30-\mathrm{mol} \%$ ) were prepared using $\mathrm{TeO}_{2}$ (Aldrich 99\%), $\quad \mathrm{Bi}_{2} \mathrm{O}_{3} \quad$ (Aldrich 99.9\%), $\quad \mathrm{H}_{3} \mathrm{BO}_{3}$ (Aldrich 99.9\%), $\mathrm{TiO}_{2}$ (Aldrich 99.9\%) by meltquench technique. Appropriate amounts of chemicals were weighed, and put in a platinum crucible after grinding and mixing chemicals. Sintering of the batch mixture was done at $250^{\circ} \mathrm{C}$ for $24 \mathrm{~h}$ in an electric furnace. The temperature of the furnace was then slowly raised to $900^{\circ} \mathrm{C}$ and the melt was kept at this temperature for $1 \mathrm{~h}$, before quenching it on a heavy brass plate. Glasses without $\mathrm{B}_{2} \mathrm{O}_{3}$ were prepared by 
splat quenching as these required higher cooling rates. The samples were characterized by density, XRD, DSC, UV-visible and Raman studies.

\section{RESULTS AND DISCUSSIONS}

XRD measurements were performed on Bruker D8 Focus X-ray Diffractometer using $\mathrm{Cu} \mathrm{K} \mathrm{K}_{\alpha}$ radiation in the $2 \theta$ range of $15^{\circ}$ to $70^{\circ}$. Sharp peaks were absent in the XRD patterns but a broad hump in the range of $22^{\circ}$ to $34^{\circ}$ was present in all glasses, which confirmed the amorphous structure of all samples [Figure 1].

Density measurements were made by Archimedes method on an electronic balance. Density of samples increases from $5.67 \mathrm{~g} \mathrm{~cm}^{-3}$ in the sample: 5TiTe to $6.12 \mathrm{~g} \mathrm{~cm}^{-3}$ in the sample: 5Ti5BiTe, on incorporating $\mathrm{Bi}_{2} \mathrm{O}_{3}$ due to the high molecular weight of $\mathrm{Bi}_{2} \mathrm{O}_{3}$ (M.Wt $=465.96 \mathrm{amu}$ ) compared to that of $\mathrm{TeO}_{2}$ (M.Wt $=159.6 \mathrm{amu})$. It is found that with the increase in the $\mathrm{B}_{2} \mathrm{O}_{3}$ concentration $(\mathrm{M} . \mathrm{Wt}=69.62 \mathrm{amu}$ ) and also $\mathrm{TiO}_{2}(\mathrm{M} . \mathrm{Wt}=79.90 \mathrm{amu})$ the density of glasses decreases as these lighter constituents replace the heavier $\mathrm{TeO}_{2}$. Variation of density and molar volume along with DSC results are given in Table 1.

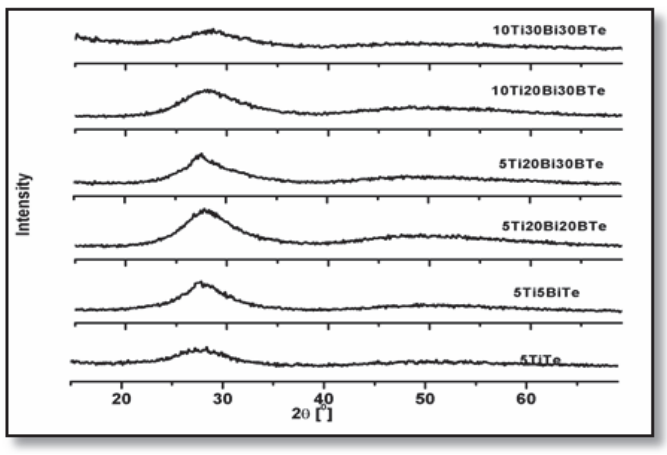

FIGURE 1. XRD patterns of glass samples.

DSC studies for the measurement of thermal properties such as glass transition temperature $\left(\mathrm{T}_{\mathrm{g}}\right)$, crystallization temperature $\left(T_{c}\right)$ and the liquidus temperature $\left(\mathrm{T}_{\mathrm{m}}\right)$ was performed on SETARAM SETSYS Evolution-1750 system in the temperature range of $200-750^{\circ} \mathrm{C}$ at a heating rate of $10^{\circ} \mathrm{C} / \mathrm{min}$, in air flow of $20 \mathrm{ml} / \mathrm{min}$. $\mathrm{T}_{\mathrm{g}}$ increases significantly from $323^{\circ} \mathrm{C}$ to $394^{\circ} \mathrm{C}$ with increase in $\mathrm{B}_{2} \mathrm{O}_{3}$ content due to greater bond enthalpy of $\mathrm{B}-\mathrm{O}$ bonds $\left(804 \mathrm{~kJ} \mathrm{~mol}^{-1}\right)$ compared to that of Te-O bonds $\left(376 \mathrm{~kJ} \mathrm{~mol}^{-1}\right)$. It was found that $\mathrm{T}_{\mathrm{g}}$ increases with increase in the concentration of both $\mathrm{TiO}_{2}$ and $\mathrm{Bi}_{2} \mathrm{O}_{3}$. The increase in $\mathrm{T}_{\mathrm{g}}$ for both $\mathrm{Bi}_{2} \mathrm{O}_{3}\left(337.2 \mathrm{~kJ} \mathrm{~mol}^{-1}\right)$ and $\mathrm{TiO}_{2}(666 \mathrm{~kJ}$ $\mathrm{mol}^{-1}$ ) indicates that the Ti-O-Te and Bi-O-Te bonds are stronger than Te-O-Te linkages [3].

UV-visible studies for the measurement of optical absorption spectra of the polished disk shaped glass samples were performed on Shimadzu 1601 double beam UV-visible spectrophotometer in the wavelength range of 200-1100 $\mathrm{nm}$. The absorption coefficient $\alpha(\lambda)$ was determined by dividing the absorbance A, with the thickness of glass samples and is shown in Figure 2.

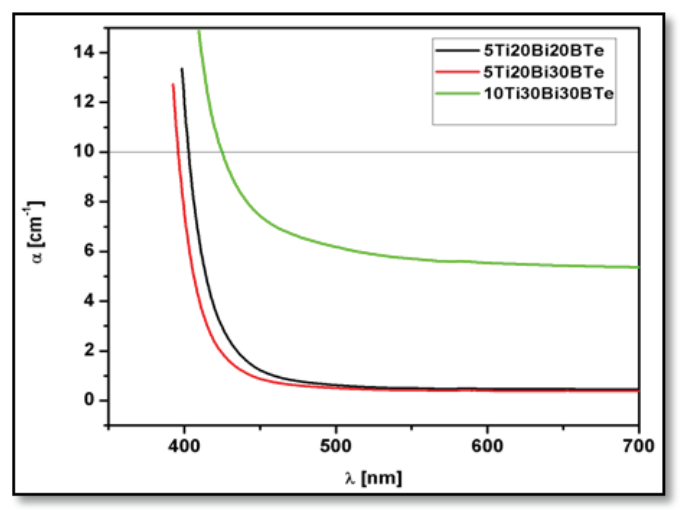

FIGURE 2. Optical absorption spectra of bismuth and titanium borotellurite glasses.

Optical band gap, $\mathrm{E}_{\mathrm{g}}$ was calculated from the cutoff wavelength $\lambda_{0}$, which was arbitrarily defined as the wavelength at which $\alpha=10 \mathrm{~cm}^{-1}$. $\lambda_{0}$ shifts to lower wavelengths as the content of $\mathrm{B}_{2} \mathrm{O}_{3}$ is increased, while it shifts to larger wavelengths with increase in $\mathrm{Bi}_{2} \mathrm{O}_{3}$ mol\% [Table 2].

$\mathrm{E}_{\mathrm{g}}$ was used to calculate refractive index, $\eta[3]$. With increase in the $\mathrm{Bi}_{2} \mathrm{O}_{3}$ content, $\mathrm{E}_{\mathrm{g}}$ decreases and $\eta$ increases because $\mathrm{Bi}^{3+}$ ions have high polarity that leads to breaking of bridging oxygen to non-bridging oxygen (NBO). The increase in the band gap with increase in $\mathrm{B}_{2} \mathrm{O}_{3}$ content is due to the decrease in the

TABLE 1. Density, DSC and $\mathrm{N}_{\mathrm{Te}-\mathrm{O}}$ results of tellurite and borotellurite glasses containing $\mathrm{Bi}_{2} \mathrm{O}_{3}$ and $\mathrm{TiO}_{2}$.

\begin{tabular}{|c|c|c|c|c|c|c|c|}
\hline \multirow[t]{2}{*}{ Sample Code } & \multicolumn{4}{|c|}{ Composition (mol\%) } & \multirow{2}{*}{$\begin{array}{l}\text { Density }( \pm 0.01) \\
\quad\left(\mathrm{g} \mathrm{cm}^{-3}\right)\end{array}$} & \multirow{2}{*}{$\begin{array}{c}\mathbf{T}_{\mathrm{g}} \\
\left({ }^{\circ} \mathbf{C}\right)\end{array}$} & \multirow[t]{2}{*}{$\mathbf{N}_{\mathrm{Te}-\mathrm{O}}$} \\
\hline & $\mathrm{TiO}_{2}$ & $\mathbf{B i}_{2} \mathbf{O}_{3}$ & $\mathbf{B}_{2} \mathbf{O}_{3}$ & $\mathrm{TeO}_{2}$ & & & \\
\hline 5TiTe & 5 & - & - & 95 & 5.67 & 323 & 3.65 \\
\hline 5Ti5BiTe & 5 & 5 & - & 90 & 6.12 & 328 & 3.50 \\
\hline 5Ti20Bi20BTe & 5 & 20 & 20 & 55 & 6.15 & 383 & 3.33 \\
\hline 5Ti20Bi30BTe & 5 & 20 & 30 & 45 & 5.93 & 394 & 3.31 \\
\hline 10Ti20Bi30BTe & 10 & 20 & 30 & 40 & 5.82 & 406 & 3.28 \\
\hline 10Ti30Bi30BTe & 10 & 30 & 30 & 30 & 6.39 & 410 & 3.22 \\
\hline
\end{tabular}


NBO concentration.

TABLE 2. Optical properties of tellurite and borotellurite glasses containing $\mathrm{Bi}_{2} \mathrm{O}_{3}$ and $\mathrm{TiO}_{2}$.

\begin{tabular}{cccc}
\hline Sample Code & $\lambda_{o}[\mathrm{~nm}]$ & $\mathbf{E}_{\mathrm{g}}[\mathrm{eV}]$ & $\eta$ \\
\hline 5Ti20Bi20BTe & 403 & 3.08 & 2.37 \\
5Ti20Bi30BTe & 396 & 3.14 & 2.35 \\
10Ti30Bi30BTe & 425 & 2.92 & 2.42 \\
\hline
\end{tabular}

Raman studies were performed on samples with Renishaw In-via Reflex micro-Raman spectrometer using $514.5 \mathrm{~nm}$ argon ion laser as excitation source, in the wavenumber range: 300 to $1000 \mathrm{~cm}^{-1}$. Short-range structural properties of the glasses were elucidated from Raman studies. Raman spectra of glass samples are shown in Figure 3.

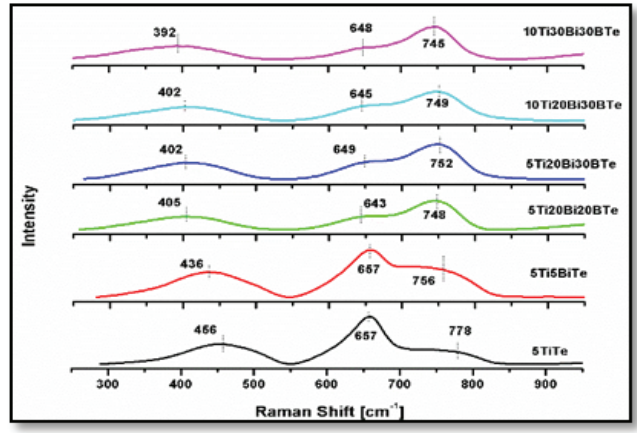

FIGURE 3. Raman spectra of tellurite and borotellurite glasses containing $\mathrm{Bi}_{2} \mathrm{O}_{3}$ and $\mathrm{TiO}_{2}$.

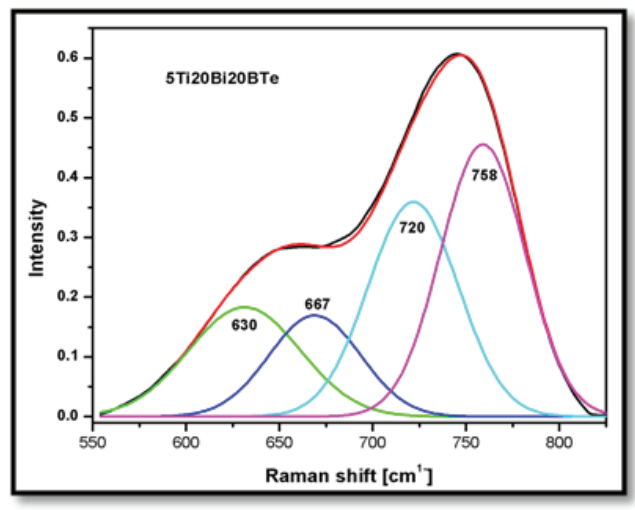

FIGURE 4. Deconvoluted Raman spectra of 5Ti20Bi20BTe glass sample.

Two characteristic Raman bands are observed in the wavenumber range: 400 to $500 \mathrm{~cm}^{-1}$ and 550 to 830 $\mathrm{cm}^{-1}$. With the addition of modifier $\mathrm{Bi}_{2} \mathrm{O}_{3}$, the band in the range: 300 to $500 \mathrm{~cm}^{-1}$ shifts towards $300 \mathrm{~cm}^{-1}$ thus indicating that the stronger Te-O-Te and Te-O-Ti bridges are replaced by weaker Te-O-Bi linkages, relative to the spectrum of crystalline $\mathrm{Bi}_{2} \mathrm{Te}_{4} \mathrm{O}_{11}$ [4] The presence of Raman peak at $450 \mathrm{~cm}^{-1}$ is due to the stretching and bending vibrations of Te-O-Te linkages in $\mathrm{TeO}_{4}, \mathrm{TeO}_{3+1}$ and $\mathrm{TeO}_{3}$ structural units. The band at $\sim 650 \mathrm{~cm}^{-1}$ is due to the Te-O stretching vibrations in $\mathrm{TeO}_{4}$. The peak at $750-760 \mathrm{~cm}^{-1}$ becomes more prominent with the increasing content of $\mathrm{Bi}_{2} \mathrm{O}_{3}$ and is due to the stretching vibrations of Te-O bonds in $\mathrm{TeO}_{3}$. This suggests that $\mathrm{Bi}_{2} \mathrm{O}_{3}$ causes an increase in $\mathrm{TeO}_{3}$ at the expense of $\mathrm{TeO}_{4}$ structural groups.

Raman spectra was de-convoluted and the peaks centered at $\sim 630,667,720,758 \mathrm{~cm}^{-1}$ were obtained, as shown in Figure 4 for one sample. The area under the peaks was used to calculate $\mathrm{Te}-\mathrm{O}$ co-ordination using the formula [3]:

$$
N_{T \theta-O}=3+\frac{A_{680}+A_{667}}{A_{680}+A_{667}+A_{720}+A_{758}} \quad 1
$$

The Te-O co-ordination number decreases from 3.50 to 3.22 on incorporating $\mathrm{B}_{2} \mathrm{O}_{3}$. This decrease in $\mathrm{N}_{\mathrm{Te}-\mathrm{O}}$ is due to the transformation of $\mathrm{TeO}_{4}$ into $\mathrm{TeO}_{3}$ structural units $[3,4]$.

\section{CONCLUSIONS}

Tellurite and borotellurite glasses containing $\mathrm{TiO}_{2}$ and $\mathrm{Bi}_{2} \mathrm{O}_{3}$ were fabricated and characterized by density, XRD, DSC, Raman and UV-visible studies. Density increases with increase in $\mathrm{Bi}_{2} \mathrm{O}_{3}$ due to its higher molecular weight. Glass transition temperature increases with both $\mathrm{TiO}_{2}$ and $\mathrm{Bi}_{2} \mathrm{O}_{3}$, although Te-O coordination is not significantly modified by $\mathrm{TiO}_{2}$. Glass forming ability of tellurite glasses containing $\mathrm{TiO}_{2}$ and $\mathrm{Bi}_{2} \mathrm{O}_{3}$ enhances significantly on incorporating $\mathrm{B}_{2} \mathrm{O}_{3}$ into the tellurite network and is due to the structural transformation: $\mathrm{TeO}_{4} \rightarrow \mathrm{TeO}_{3}$.

\section{ACKNOWLEDGEMENT}

Financial support from DST-Indo-Bulgarian project is acknowledged.

\section{REFERENCES}

1. R.A. El-Mallawany, Tellurite Glasses Handbook: physical properties and data. 2011: CRC Press.

2. M. Soulis, T. Merle-Méjean, A.P. Mirgorodsky, O. Masson, E. Orhan, P. Thomas and M.B. Smirnov, Journal of Non-Crystalline Solids 354, 199-202 (2008).

3. N. Kaur and A. Khanna, Journal of Non-Crystalline Solids 404, 116-123 (2014).

4. M. Udovic, P. Thomas, A. Mirgorodsky, O. Durand, M. Soulis, O. Masson, T. Merle-Méjean and J.C. Champarnaud-Mesjard, Journal of Solid State Chemistry 179, 3252-3259 (2006). 